\title{
Reform and Exploration on Electric Circuit Course Teaching Based on CDIO
}

\author{
Yuanbin Wang \\ School of Electric \& Controll Engineering, Xi'an University of Science \& Technology, Xi'an, China \\ Email: wangyb998@163.com
}

Received 18 January 2016; accepted 25 March 2016; published 28 March 2016

Copyright (C) 2016 by authors and Scientific Research Publishing Inc.

This work is licensed under the Creative Commons Attribution International License (CC BY). http://creativecommons.org/licenses/by/4.0/

\section{(c) (i) Open Access}

\begin{abstract}
In light of the current problems about Electric Circuit course teaching in universities, the problems in the current teaching of the course are presented and analyzed. The international idea of CDIO is put forward and introduced, and this educational mode is applied in Electric Circuit course teaching. Reform is made to change the current situation that students are weak in experiments and practice links, and concrete measures are proposed. It is shown that this teaching mode can help students not only to promote the understanding and grasp the knowledge points but also it can improve the innovation ability, engineering ability and cooperation ability, communication ability effectively. It will be helpful both to the graduates and society. This teaching mode proposed is effective and feasible.
\end{abstract}

\section{Keywords}

\section{CDIO, Engineering Education, Electric Circuit, Reform of Teaching}

\section{Introduction}

With the rapid development of science and technology in globe, higher requirement is proposed for all the engineers. The education reform is becoming an inevitable and significant project. Industrial civilization ideology must be strengthened in high school. Cultivating innovative talents need enhance experiments and engineering practice, at the same time general knowledge education should be associated with experiments and practice (Zuo \& Lin, 2010; Gu, 2009). The traditional students in electric and electronic field attach more importance to theory but despise practice, emphasize the individual academic ability and ignore team cooperation spirit, stress knowledge learning but contempt the cultivating of innovation. Consequently this leads to the weak application ability and poor comprehensive quality. It is difficult for them to adapt the society and enterprise (Guo, Yan, Ying, \& Chen, 2011). CDIO is a novel international mode which has included conceive, design, implementation and operates for higher engineer education, and it is highly advocated by Massachusetts Institute of Tech- 
nology and other three famous universities initially. CDIO methods are used in Shantou University and Tsinghua University. Outstanding results have been achieved. It has been verified that the idea of CDIO is scientific and feasible.

Some problems associated with teaching are discussed in this paper, and the concept of CDIO is introduced in the teaching of Electric Circuit, then the reform and practice based on CDIO are explored. Measures are put forward to enhance the technology ability, engineering ability.

\section{CDIO Education Mode}

CDIO is a kind of advanced teaching mode which is built by Massachusetts Institute of Technology by 4 years study, exploring and teaching practice. It is a novel teaching mode based on project education and learning. It has inherited and developed the engineering education concept from Europe and America, and it is aimed at cultivating the engineering ability, team spirit and cooperation ability. It is a guide and direction for cultivating the innovative talents (Jiang, Sun, 2012; Hu \& Ren, 2010; Li, 2008). It is also extremely meaningful to the teaching and practice reform for the technology courses in colleges. Traditional teaching modes usually emphasize theory knowledge and individual academic ability a lot, while pay little attention to practice and team cooperation, thus leading to the weak application ability and career accomplishment of the students, finally it is difficult for them to adaptive to the society and enterprise. CDIO mode pays more attention to the fundamental theory and specialized knowledge, culturing ability can be realized by each mode and each teaching loop. This teaching mode can enhance the self learning ability, problem-solving ability and team cooperation of the students. It is meaningful to technology teaching (Wang \& Hong, 2009; Ma, Zhang, \& Qiao, 2010; Cao \& Liang, 2012).

\section{Problems in the Traditional Teaching of Electric Circuit}

For the teaching of electric circuit, traditional teaching mode is employed in most universities currently which is called LBL (Lecture-Based Learning) mode. It is a kind of study based on lecturer and students often accept the knowledge passively. The direction and contents of the teaching are determined by teachers, teaching goals and schedule are mastered by teachers. Consequently, students play a passive role in learning. This teaching method is difficult to mobilize the initiative of students, and the potential of students hasn't been excavated deeply, then the interaction between teachers and students is difficult to implementation. Students can't grasp the contents truly and they are weak in active practice links.

With the development of electric and electronics, requirements from different aspects are enhanced. However, according to cultivating talents, problems are existing in the following.

\subsection{The Traditional Teaching Concepts}

The features of Electric Circuit course are like the following, the specialty is difficult, while the theory and practice should be associated together highly. Nowadays most of the theory system is taken as frame in the theory teaching mode, language description, blackboard writing and textbook are the most important form, the whole class hour is taught to the students, and the entire process attach importance the theory and despise the practice, which is inconsistent with that both the theory and practice are significant. It is difficult to mobilize the interest of students to study harder.

\subsection{Theory Knowledge Disjointing with Practice}

Practice link is a very significant loop for the Electric Circuit teaching. It is usually implemented after the theory knowledge is learned, and students follow the guide book to make the interrelated experiments. It is unnecessary to design any experiment, and it is not easy to mobilize the enthusiasm of the students (Han \& $\mathrm{Li}, 2012$ ) Consequently, students are feeble in operating ability, active learning, innovative ability, team cooperation ability.

\section{Reform Measure of Electric Circuit Course Based on CDIO}

In view of the above problems, we make reform on Electric Circuit course based on CDIO. In the reform, active project-driven learning method is employed and knowledge points are taught to students actively (Pan, 2013). 
Theory contents and practice are associated closely in practice links, integrated teaching is realized, the ability solving problems, team cooperation ability and engineering ability are all improved greatly.

\subsection{Teachers Becoming a Project Designer from a Knowledge Propagator}

According to the concepts of CDIO, the idea of large-scale engineering means that engineering education emphasizes the discipline knowledge and technology simultaneously, however, in the past engineering education pays attention to the theory singly. Consequently, teachers arranged the teaching contents and schedule rationally, furthermore, they should design out the integrated teaching plan that can promote the technology ability, and the detached knowledge points form a correlated knowledge net. More colorful design projects should be arranged. Teaching system of Electric Circuit Course based on CDIO is built in Figure 1. At the same time, conceive, design, implement and operation all should be included in the plan. Students should be encouraged to take part in it and involve more. For example, firstly, the computation of one port circuit is proposed, then students should realize the circuit design at the inspiration of teachers, and PSPICE simulation experimentation should be implemented, finally, the practical application can be made by means of examples. Thevenin's theorem can be proved by superposition theorem.

\subsection{Associating Practice with Scientific Research, Enhancing the Connection among Teaching}

When some significant knowledge points are taught, the frontal achievements home and abroad should be given to students in the class and stimulate the interest of students to investigate further. Engineering examples are introduced into the class. Consequently, teachers make their best to associate with scientific research, production practice, academic frontier, technology, and specialized skill. On the other hand, the projects shouldn't be too large and too difficult, and follow the rational gradual principle in order to understand the contents better. For example, when series resonance and parallel resonance are taught in the class, application on radio and current development should be also given to students. Thus this can promote the thirst for knowledge, emphasize the contents, deepen the understanding about theory knowledge and engineering application, and improve the teaching results.

\section{Conclusion}

Electric Circuit is a basic specialized course and has strong practice features. To change the traditional mode, the

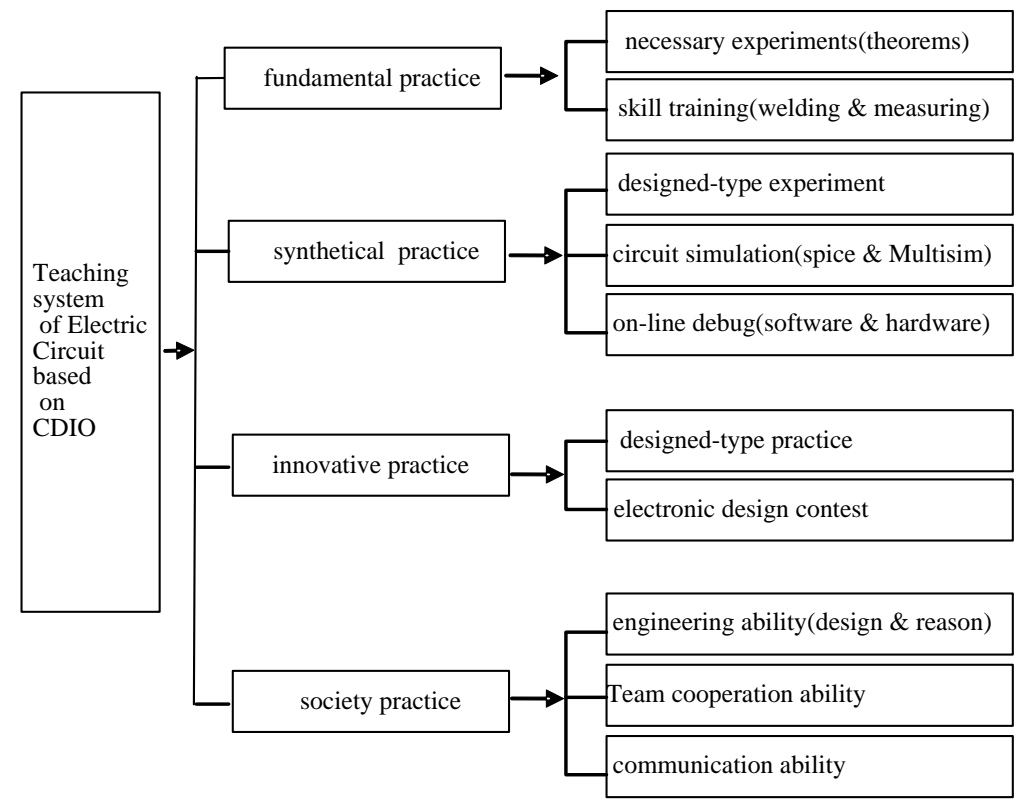

Figure 1. Teaching system of Electric Circuit course based on CDIO. 
concepts of CDIO are employed, the new teaching mode based on CDIO is discussed, and reform from teaching form, examination form and ability cultivating are made. It is shown that it can mobilize the subjective initiative of students greatly. It can deepen the understanding of the fundamental knowledge, but also improve the engineering ability, application ability and cooperation ability. At the same time, it has reference and popularized meaning to other courses.

\section{Acknowledgements}

This research is financially supported by XUST of education and reform project (Grant No. JG14003).

\section{References}

Cao, M. S., \& Liang, Z. X. (2012). On the Transformation of Higher Engineering Professional Teacher's Role Based on the Concept of CDIO. Research in Higher Education of Engineering, 1, 21-24.

Gu, X. Y. (2009). Connecting Abstract Theories with Concrete Engineering Skills in the CDIO Learning Cycle. Research in Higher Education of Engineering, 1, 42-45.

Guo, J., Yan, P., Ying, H., \& Chen, X. F. (2011). Experiment Teaching Reform for Computer Majors Based on CDIO. Experimental Technology and Management, 28, 155-157.

Han, G. Y., \& Li, X. Z. (2012). Exploration and Practice on Projective-Driven Teaching of Digital Circuit under Perspective. Research and Exploration in Laboratory, 26, 168-172.

Hu, Z. G., Ren, S. B., \& Chen, Z. G. (2010) Program Optimization Based on CDIO-CMM for Undergraduate Education in Engineering. Research in Higher Education of Engineering, 6, 30-33.

Jiang, D. Z., \& Sun, H. J. (2012). On CDIO-Based on Active Project-Driven Learning Method. Research in Higher Education of Engineering, 4, 44-47.

Li, M. L. (2008). An Historical Interpretation of CDIO and Its Application Prospects. Tsinghua Journal of Education, 29, 78-81.

Ma, X. M., Zhang, J. F., \& Qiao, F. (2010) Reform and Exploration of Higher Engineering Education Based on CDIO. Computer Education, 12, 35-38.

Pan, X. P. (2013). Reform of Experimental Teaching of Digital Circuit Based on CDIO. Research and Exploration in Laboratory, 32, 400-403.

Wang, S. H., \& Hong, C. W. (2009). CDIO: The Classic Mode of Engineering Education in MIT. Journal of Higher Education in Science \& Technology, 28, 116-119.

Zuo, T. Y., \& Lin, Z. P. (2010). Engineer Practice Education Must Be Strengthened. Research and Exploration in Laboratory, 29, 1-5. 